\title{
EFFECT OF MODULUS OF MASONRY ON INITIAL LATERAL STIFFNESS OF INFILLED FRAMES WITH OPENINGS
}

\author{
Bhagyalaxmi sindagi ${ }^{1}$, Anusha P Gowda ${ }^{2}$, Harshitha R Kumar ${ }^{3}$, M V Renukadevi ${ }^{4}$ \\ ${ }^{I} P G$ Student (2009-2012), Department of Civil Engineering, $R$ V College of Engineering, Bangalore \\ ${ }^{2} P G$ Student, Department of Civil Engineering, $R V$ College of Engineering, Bangalore \\ ${ }^{3} P G$ Student, Department of Civil Engineering, $R V$ College of Engineering, Bangalore \\ ${ }^{4}$ Associate professor, PG Studies, Department of Civil Engineering, $R$ V College of Engineering, Bangalore.
}

\begin{abstract}
Masonry infills are commonly used in buildings for functional and architectural reasons. The structural contribution of infill walls cannot simply be neglected particularly in regions of moderate and high seismicity where the frame-infill interaction may cause substantial increase in both stiffness and strength of the frame in spite of the presence of openings. In the present study an attempt is made to study the initial lateral stiffness of the infilled frames with central opening of different sizes for varying modulus of masonry (2750 Mpa and $1000 \mathrm{Mpa}$ modulus) using the finite element analysis. The percentage reduction in the initial lateral stiffness of infilled frames due to varying modulus of masonry is obtained. The initial lateral stiffness of infilled frame is also determined by single equivalent diagonal strut analysis by varying the width of strut and a strut-width-reduction factor is proposed to determine the strut width for the opening present in the infill panel.
\end{abstract}

Keywords: infilled frame, modulus of masonry, lateral stiffness, and effect of openings.

\section{INTRODUCTION}

Masonry is one of the oldest construction materials currently in use around the world for reasons that include accessibility, functionality, and cost. This material has been used for hundreds of years in construction projects ranging from simple roadways to complex arch designs. Masonry has also commonly been used in frame building structures as infill, where it was intended to act as an environmental divider rather than a structural element. The primary function of masonry was either to protect the inside of the structure from the environment (rain, snow, wind, etc.) or to divide inside spaces. In either case, common practice has always been to ignore infill during the design and analysis of steel/reinforced concrete frame structures. However, infill wall tend to interact with the surrounding frame when the structure is subjected to wind or earthquake loads; the resulting system is referred to as an infilled frame.

In such structures the ordinarily occurring vertical loads, dead or live loads do not pose much of a problem in the analysis and design. But the in-plane lateral loads due to wind and earthquake, tremors or blast loads are a matter of great concern and need special consideration in the design of buildings. These lateral forces can produce the critical stresses in a structure, set undesirable vibrations and in addition cause lateral sway of the structure to such an extent that it would reach a stage of discomfort to the occupants. Some of the lateral load resistance structures used in practice is shown in the (Fig.1). Diagonal bracing (Fig 1a) can be conveniently adopted in steel frames. Reinforced concrete frames cannot be provided with such braces; however monolithic joints will provide resistance to some extent (Figlb). Relying only on rigid joint would result in expensive columns, which have to resist large resulting moments. Provision of reinforced concrete shear walls in the plane of the loads at the selected location in the building scheme (Fig 1c) for tall buildings is the modern trend of construction that is widely resorted to in order to reduce lateral sway and achieve economy in the design. Stair wall and elevator shafts are designed on the basis of principal of shear wall.

However, with the increasing cost of steel and cement these structures are becoming expensive and added to that the shallow structures do not such lateral load resisting systems. Infilled frames can be thought of an alternative where in the masonry wall providing for partitioning and covering without any structural functions can impart substantial stiffness and strength to bounding frame against lateral load.

Efforts have been made by many researchers to exploit the inherent lateral stiffness and strength of the masonry infilled frames. It has been well recognized that the brickwork infill is very effective in bracing of frames composed of beams and columns to resist in-plane lateral loads. But the same has not featured in most of the codes of practices with an acceptable design procedure. This is probably because of the inherent weakness of the brickwork infill in resisting tensile stresses induced by racking loads particularly when full contact is 
established at the interface by shear connecter or any means. Although, the stress diminishes when separation is allowed at the interface, the loaded corner faces possibilities of crushing in view of large concentration of stress.

Lateral loads do not act in isolation on a structure but act in tandem with gravity loads with varying magnitude. These loads comprise of constant dead weight of the structure and that of element supported by the frame along with live load of varying magnitude. The vertical lateral load are expected to induce pre-compression to the masonry infill and reduce the tensile stress induce by lateral loads. The diagonal compressive stress although increases as the result of precompression, is expected to spread over a wider area of masonry, thereby reducing the possibility of corner crushing. In developing countries like India, mass housing schemes are being executed on a massive scale to cater to the housing needs of people. Most of these structures are three to four storied building, construed usually of reinforced concrete frames with brick infill. If the structural interaction between the masonry and R.C. members is properly understood, it would result in significant reduction in the cost of construction.

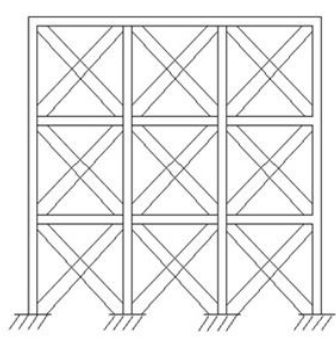

a STEFL FRAMED STRUCTURE

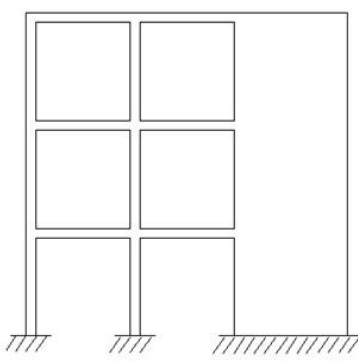

C SHEAR WALL FRAMED STRUCTURE

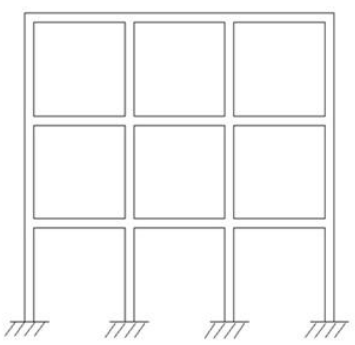

b RCC FRAMED STRUCTURE

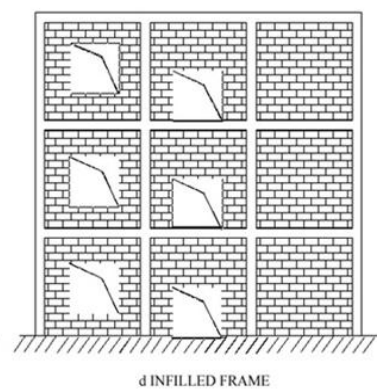

d INFILLED FRAME
Fig 1: Lateral Load resistance Structure: a) RCC framed structure b) Steel framed structure c) shear wall framed structure d) infilled frame

\section{METHODS OF ANALYSIS}

Over the past few decades, several methods for the analysis of infilled frames have been proposed in the literature by various investigators. These methods can be divided into two groups, depending on the degree of refinement used to represent the structure. The first group consists of the macro models to which belong the simplified models that are based on a physical understanding of the structure. The second group involves the micro models including the finite element formulations, taking into account local effects in detail. Both types of methods will be discussed hereafter.

\subsection{Macro Models}

The basic characteristic of the macro models is that they aim at predicting the overall stiffness and failure loads of infilled frames, without considering all possible failure modes of local failure. This group of models can be subdivided to their origin into the following three categories, based on:

$>$ the concept of the equivalent diagonal strut

$>$ the concept of the equivalent frame

\subsubsection{Equivalent Diagonal Strut Analogy}

The simplest (and most developed) method for the analysis of non-integral infilled frames is based on the concept of the equivalent diagonal strut. This concept was initially proposed by Polyakov (1956) and later developed by other investigators. In this method, the infilled frame structure is modeled as an equivalent braced frame system with a compression diagonal replacing the infill. Equivalent diagonal strut method is further subdivided into the following three categories

a) Single Diagonal Strut Model

b) Modified Diagonal Strut Model

c) Multi-Strut Model

\subsection{Micro Models}

The development of finite element methods offered some relief to the shortcomings pointed out in the previous methods. The first approach to analyze infilled frames by linear finite element analysis was suggested by Mallick and Severn (1967). They introduced an iterative technique taking into account separation and slip at the structural interface. Plane stress rectangular elements were used to model the infill while standard beam elements were used for the frame. However, as a consequence of the assumption that the interaction forces between the frame and the infill along their interface consisted of normal forces only, the axial deformation of the columns was neglected in their formulation. The effect of slip and interface friction was considered by introducing shear forces along the length of contact. The contact problem was solved by initially assuming that infill and frame nodes have the same displacement. Having determined the load along the periphery of the infill, tensile forces were located in the model. Subsequently the corresponding nodes of the frame and infill were released which allowed them to displace independently in the next iteration. This procedure was repeated until a prescribed convergence criterion was achieved. 


\section{LITERATURE REVIEW}

A summary of the major research works that have been carried out on infilled frames with and without openings has been presented in this section. Some of these experimental researches were performed on perforated infill walls with steel frames and some others on RC frames. Different types of loads such as static load, pseudo-static load, pseudo dynamic load, and dynamic load were applied in these studies. The literature survey carried out here is confined to those works that study the behavior and methods of analysis of infilled frames with and without openings.

Polyakov [17]: Is the earliest research worker to investigate the infilled frame subjected to lateral load at the central research institute for industrial structure, Moscow. From the extensive experiments on model infilled frames with different infills he studied the

Nature and cause of cracks formation, effect of opening and effect of strengthening masonry by RC element. In all these tests, he found that the initial failure was by cracking around the perimeter allowing the separation of frame and infill except at the loaded corners. From the result of POLYAKOV proposed infill as a diagonal bracing strut.

Mainstone [12]: Describes the test on the full scale and model steel frames with brick infills. The approach to the problem was based on concept of diagonal strut. It has visualized replacing infill by several or single strut depending upon the degree of initial fit of the infill to the frame. Simple equations have been derived to predict equivalent width of strut, lateral stiffness and strength of the infilled frames.

Perumal Pillai and Govindan [18]: Have studied the structural response of two quarter-size, five storey R C frame with and without brick infill and assessed the performance based on the ductility and energy absorption capacity. The frames were tested under static reversed cyclic loading to stimulate seismic effects. The study covers the entire elastic loading range from the initial elastic stage until the ultimate failure stage. The comparison of experimental and theoretical results is reported to be generally good. The failure mechanism in such case is brittle.

Goutam Modal And Sudhir K. Jain [6]: Have carried out a parametric finite element analysis on single bay, single story, single bay two story and single bay three story infilled frame to examine the effect of central openings of different sizes on the initial stiffness of infilled frames. Based on the study he has concluded the effect of opening on the initial lateral stiffness of infilled frames should be neglected if the area of opening is less than $5 \%$ of the area of the infill panel, and the strut width reduction factor should be set equal to one i.e. the frame is to be analyzed as a solid infilled frame. The effect of infill on the initial lateral stiffness of infilled frame may be ignored if the area of opening exceeds $40 \%$ of the area of the infill panel, and the strut-width reduction factor should be set to zero, i.e. the frame is to be analyzed as a bare frame. The proposed reduction factor is applicable for infilled frame with normal openings. Extreme cases where openings are extended to full height or full width of the infilled frame cannot be covered by the reduction factor.

\section{OBJECTIVE OF THE STUDY}

Masonry infills are commonly used in buildings for functional and architectural reasons. However, their structural contributions are usually neglected in the design process. Behavior of building in the recent earthquake, clearly illustrate that the presence of infill walls has significant structural implications. The difficulties in considering infill walls in the design processes are due to the lack of experimental and analytical results about their behavior under lateral seismic shaking. The structural contribution of infill walls cannot simply be neglected particularly in regions of moderate and high seismicity where the frame-infill interaction may cause substantial increase in both stiffness and strength of the frame in spite of the presence of openings, but the presence of opening decreases stiffness and strength of the infilled frame. Generally, the type of bricks varies from one place to another place; in turn this affects the modulus of masonry. In view of this, the present study focuses on the effect of modulus of masonry on the initial lateral stiffness of infilled frame.

The following parametric study has been carried out:

> The initial lateral stiffness of single bay, single story infilled frame with central openings, with brick masonry as infill subjected to lateral load for varying modulus of masonry by finite element method of analysis using the software ANSYS.

> Initial lateral stiffness is also determined by using single equivalent diagonal strut analysis.

$>$ A strut-width-reduction factor is proposed to determine the strut width for the opening present in the infill panel.

\section{ANALYTICAL INVESTIGATION}

Finite element method is one of the most important methods of discrete analysis and has been found suitable for solution of problems. Hence the method has been used for the analysis of infilled frame taking into consideration all the factors at the interface i.e. separation at the contact surface. In this method, standard two nodded frame elements with two translations degrees of freedom and one rotational of freedom at each node are use to model the frame elements. The infills are idealized by four nodded plane stress rectangular or square area elements with two translational degrees of freedom at each node. Interface of the infill and frame are modeled using stiff beam element having three degrees of freedom at each node, the nodes connecting the infill is made of structural hinge so that no moment is transferred to the infill from the link 
element Beam/Column elements are represented by Beam 4 element chosen from element library. BEAM4 is a uniaxial element with tension, compression, torsion, and bending capabilities.

Plane 42 element is chosen to represent a masonry it is a four nodded rectangular element with two translation degrees of freedom (UX and UY) at each node.

The 3-D spar element is a uniaxial tension-compression element with three degrees of freedom at each node, translational in the nodal $\mathrm{x}, \mathrm{y}$ and $\mathrm{z}$ direction.

In the present study, single-bay single-storey is analyzed and their initial lateral stiffness for varying modulus is determined

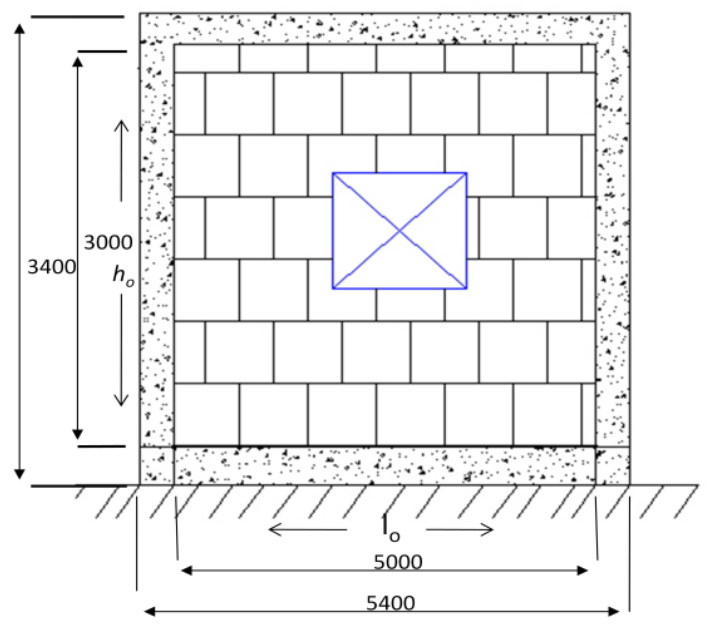

Fig 5.1: Dimensions ( $\mathrm{mm}$ ) of single-bay, single-storey infilled frame with symmetric Central opening. (beam size $250 \mathrm{~mm} x$ 400mm; column size $400 \mathrm{~mm}$ x 400mm)

Table 5.1: Properties of infilled frame

\begin{tabular}{|c|c|c|c|}
\hline Properties & Density & $\begin{array}{l}\text { Modulus of } \\
\text { elasticity } \\
\text { ( MPa) }\end{array}$ & $\begin{array}{l}\text { Poisson's } \\
\text { ratio }\end{array}$ \\
\hline Elements & $\left(\mathrm{Kg} / \mathrm{m}^{3}\right)$ & 1000 & 0.18 \\
\hline Masonry & 1920 & 25000 & 0.2 \\
\hline $\begin{array}{c}\text { Beam/ } \\
\text { Column }\end{array}$ & 2500 & 25000 & 0.2 \\
\hline Link & 0.01 & & \\
\hline
\end{tabular}

Table 5.2: Dimensions of infilled frame

\begin{tabular}{|c|c|c|}
\hline Elements & $\begin{array}{c}\text { Dimension } \\
(\mathrm{mm} \times \mathrm{mm})\end{array}$ & $\begin{array}{c}\text { Centre line } \\
\text { length }\end{array}$ \\
\hline Masonry & $\begin{array}{c}1770 \times 1770 \times \\
110\end{array}$ & 1770 \\
\hline Beam & $150 \times 230$ & 2000 \\
\hline Column & $230 \times 150$ & 2000 \\
\hline Opening & $875 \times 875$ & \\
\hline
\end{tabular}

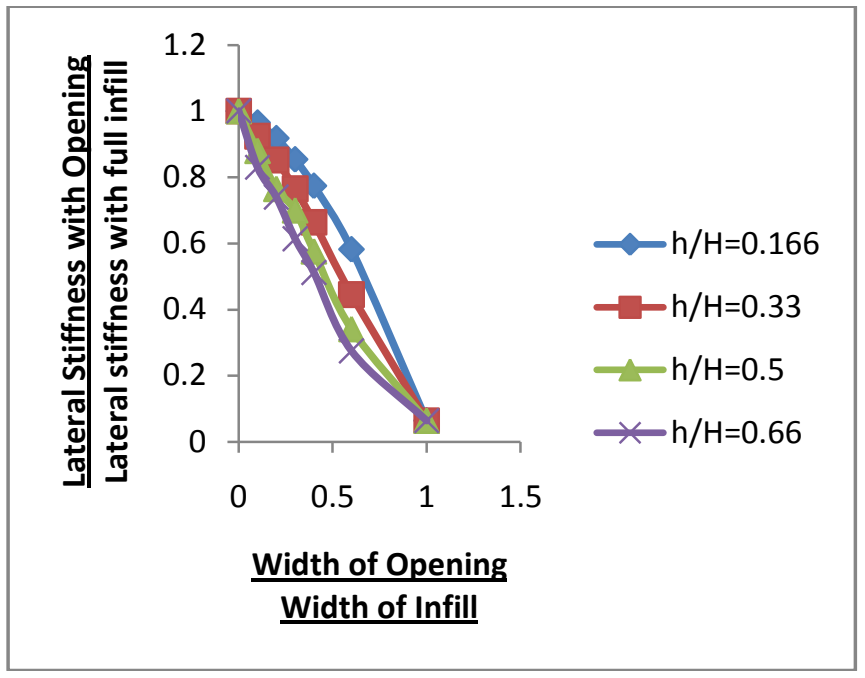

Fig 5.3: Effect of opening size on Initial lateral stiffness of Infilled frame determined by FE Analysis for $2750 \mathrm{Mpa}$ Modulus (Full Contact).

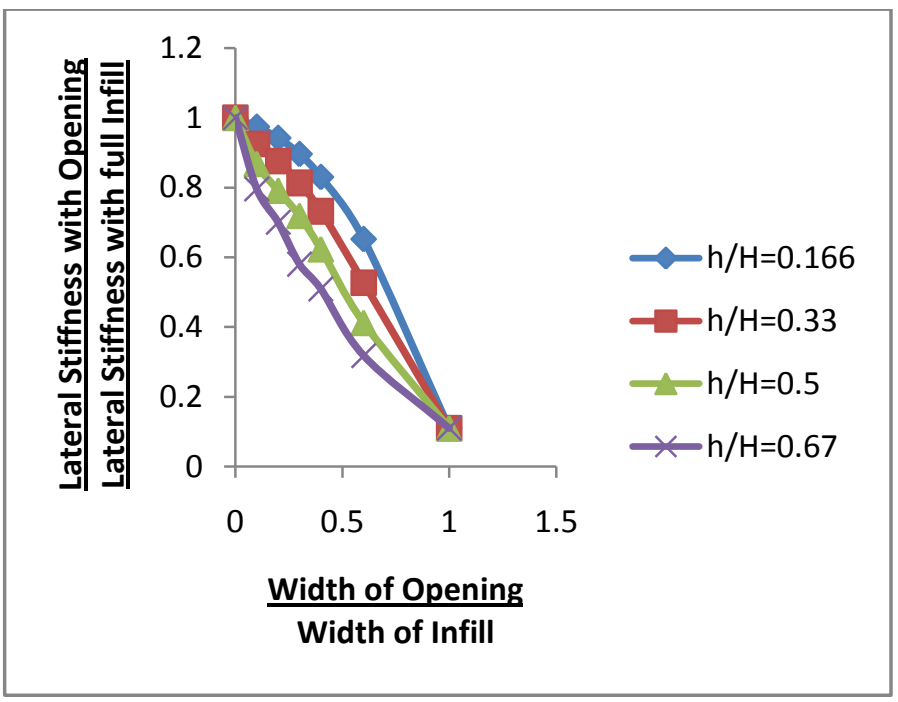

Fig 5.4: Effect of opening size on Initial lateral stiffness of Infilled frame determined by FE Analysis for $2750 \mathrm{Mpa}$ Modulus (Full Contact). 


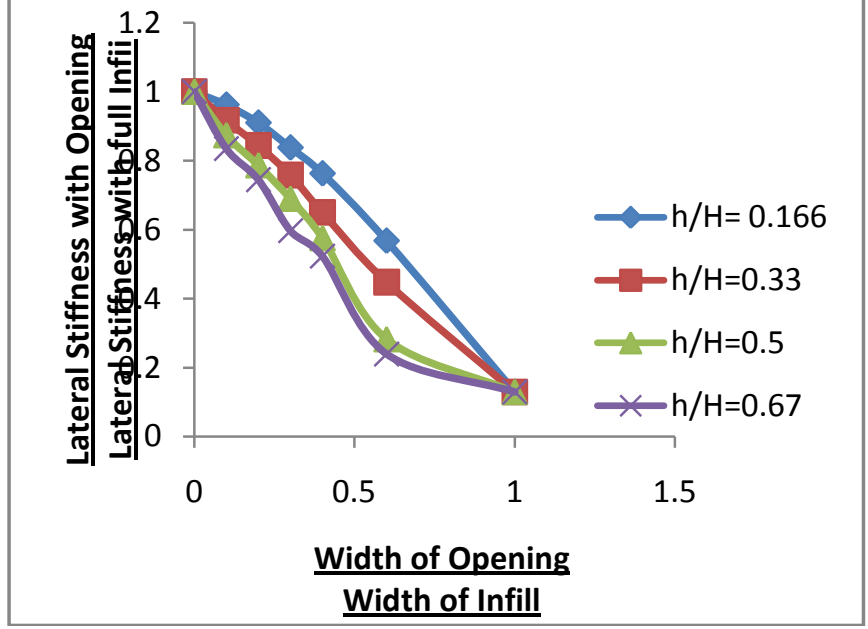

Fig 5.5: Effect of opening size on Initial lateral stiffness of Infilled frame determined by FE Analysis for $1000 \mathrm{Mpa}$ Modulus (Full contact).

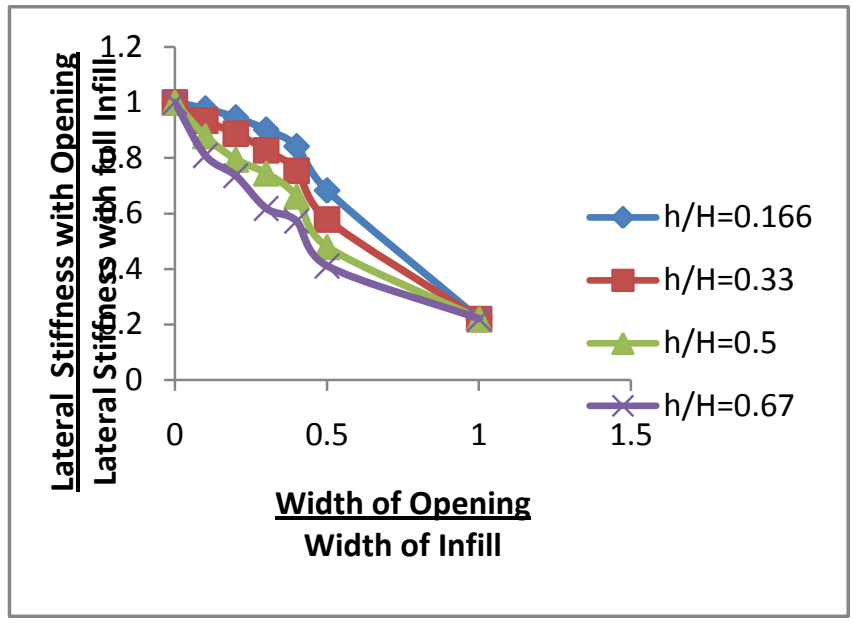

Fig 5.6: Effect of opening size on Initial lateral stiffness of Infilled frame determined by FE Analysis for $1000 \mathrm{Mpa}$ Modulus (separation case).

\subsection{Observations on Initial Lateral Stiffness of}

\section{Infilled Frame}

Based on the study and results following observation are noted

$>$ Presence of opening significantly reduces the initial lateral stiffness of infilled frame.

$>$ The lateral stiffness decrease with increase in area of opening .when the area of opening is about $15 \%$ of the initial lateral stiffness is reduced by 20 to $32 \%$.

$>$ Percentage reduction of initial lateral stiffness is found to be 52 to $53 \%$ with decrease in modulus of masonry in case of full contact case

$>$ In separation case the reduction percentage ranges from 46 to $52 \%$.

\subsection{Effect of Dimensions of Openings}

The effect of opening of dimensions of opening on initial lateral stiffness of infilled frame for varying modulus of masonry (2750 Mpa and $1000 \mathrm{Mpa}$ ) for separation case were tabulated.

\section{RESULTS AND DISCUSSION}

A study of infilled frames with varying central opening is performed in this chapter. Finite element analysis is carried out using Ansys to determine the effect of modulus on initial lateral stiffness of infilled frame for different sizes of opening Contour patterns for full contact and separation case Mpa for $2750 \mathrm{Mpa}$ modulus of masonry are shown in the figure.6.1 and 6.2

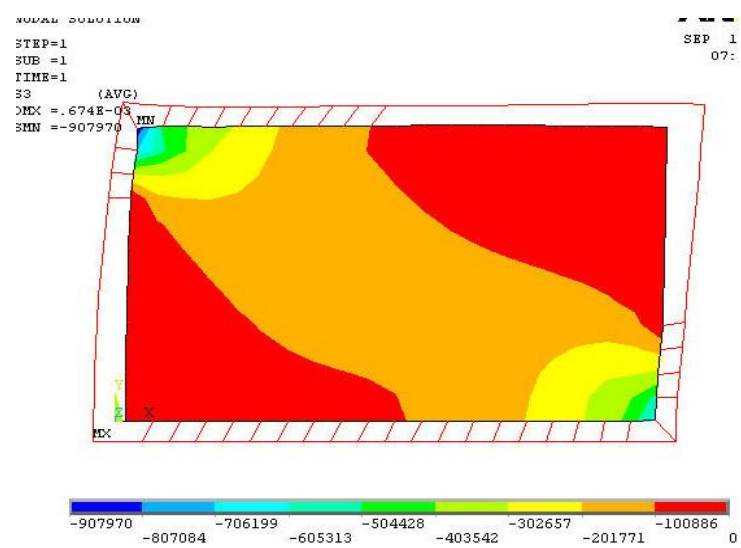

Fig 6.1: Contour Pattern for full infill, for separation case for 2750 Mpa 3rd Principal stress

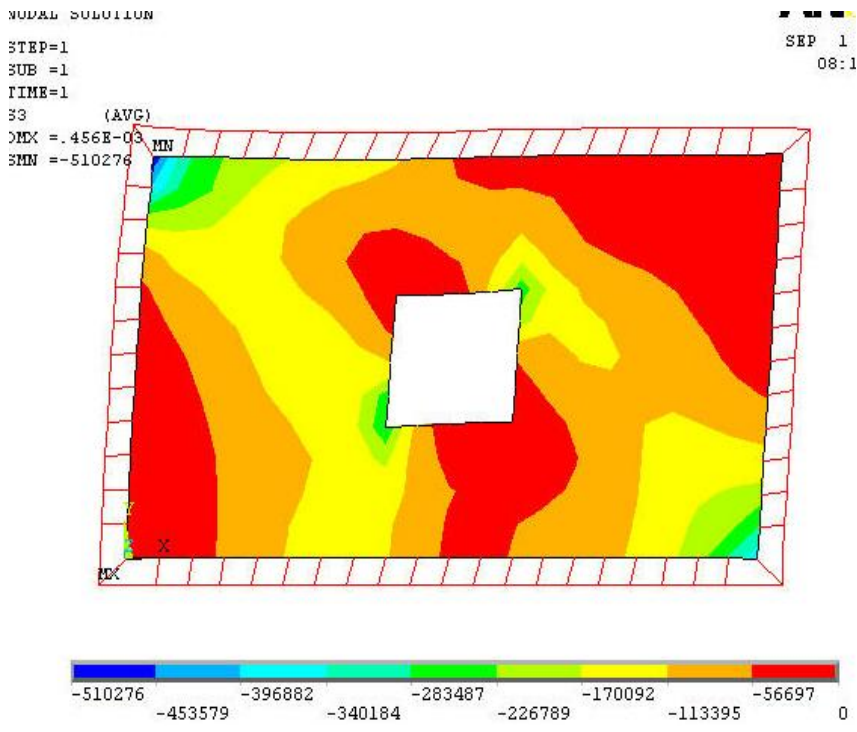

Fig 6.2: Contour patterns for $1000 \mathrm{~mm} \times 1000 \mathrm{~mm}$ opening infill, for full contact case for $2750 \mathrm{Mpa}$ modulus $3^{\text {rd }}$ Principal stress 


\section{STRUT-WIDTH REDUCTION FACTOR FOR INFILLED FRAME WITH OPENING}

Stiffness of an infilled frame can be obtained by modeling it as a diagonal strut of suitable width. The effect of opening in the infill wall is to reduce the lateral stiffness of the frame. This reduced lateral stiffness due to opening can be represented by a diagonal strut of reduced width. This reduction in strut width can be represented by a factor

$\rho_{w}$ which is defined as ratio of reduced strut width to strutwidth corresponding to fully infilled frame, i.e.

Strut width Reduction Factor( $\rho w)$

$$
=\frac{\text { Strut Width of Infilled frame with Opening(Wdo) }}{\text { Strut Width of Fully Infilled Frame (Wds) }}
$$

Area $A_{o p}$ of opening is normalized with respect to area $A_{\text {infill }}$ of infill panel and the ratio is termed as opening area ratio $\alpha_{c o}$, i.e.,

Opening Area Ratio $\left(\alpha_{c o}\right)$

$$
=\frac{\text { Area of Opening }}{\text { Area of Infill }}
$$

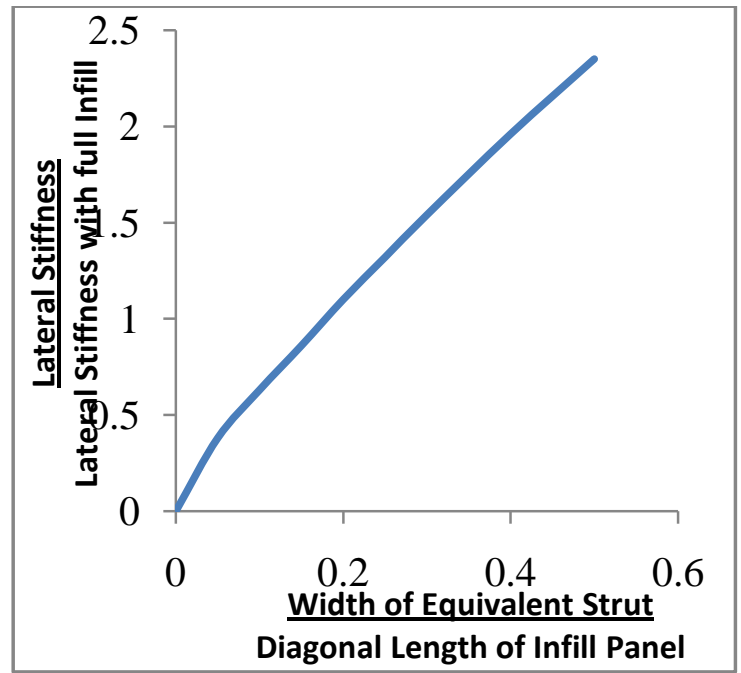

Fig 7.1: Effect of opening size on equivalent diagonal strut: a) 2750 Mpa modulus of masonry

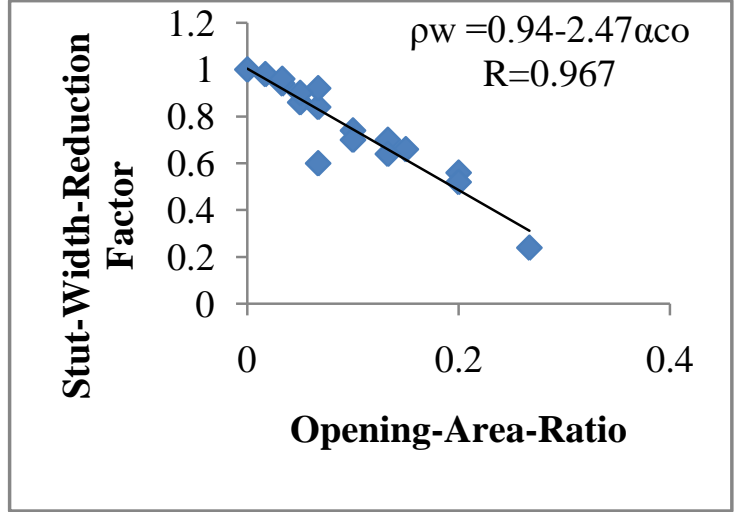

Fig 7.2: Effect of opening area ratio on strut width reduction factor: linear fit curve of analytical result $2750 \mathrm{Mpa}$ modulus of masonry

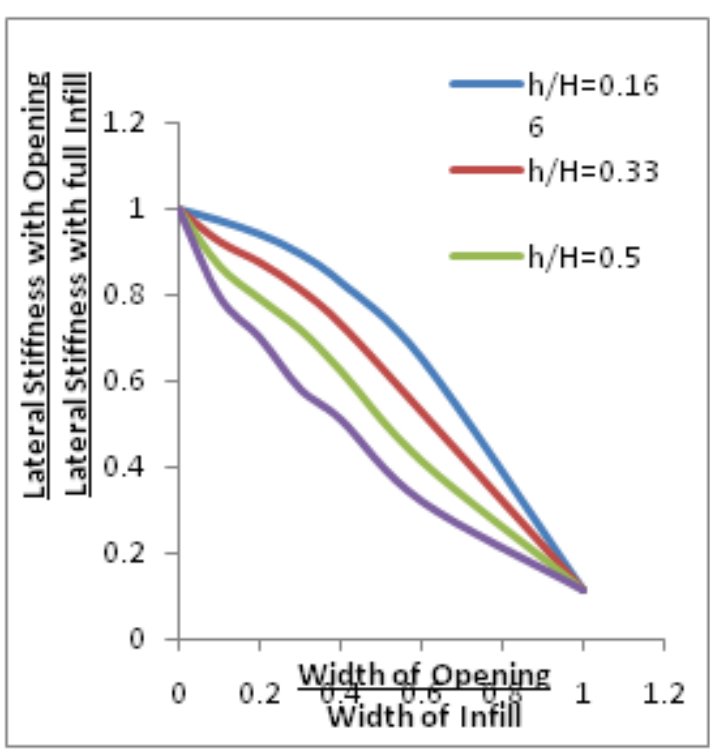

\section{CONCLUSIONS}

Presence of opening significantly reduces the initial lateral stiffness of infilled frame. The lateral stiffness decrease with increase in area of opening .when the area of opening is about $15 \%$ of the initial lateral stiffness is reduced by 20 to $32 \%$. Percentage reduction of initial lateral stiffness is found to be 52 to $53 \%$ with decrease in modulus of masonry (2750 Mpa to $1000 \mathrm{Mpa})$ in case of full contact case

In separation case the reduction percentage ranges from 46 to $52 \%$.For the same area of opening if the dimensions of opening vary, the difference in initial lateral stiffness is less than $5 \%$.

In case of two similar rectangular frames with equal areas of openings, the frame having larger width of opening exhibits more initial lateral stiffness. 
The presence of openings can be considered in the single diagonal strut model by reducing the effective width through a reduction factor, $\rho \mathrm{w}=0.94-2.47 \alpha_{c} o$, for $2750 \mathrm{Mpa}$ modulus where $\alpha_{c o}=$ ratio of the area of opening to the area of the infill.

\section{REFERENCES}

[1] Al-Chaar, G., (2002), Evaluating Strength and Stiffness of Unreinforced Masonry Structures, US Army Corps of Engineers, Construction Engineering Research Laboratories, Technical Manuscript, ERDC/CERL TR02-1, January.

[2] ATC-40, (1996), Seismic Evaluation and Retrofit of Concrete Buildings, Applied Technology Council, Redwood City, California, Vol. 1, Report No. SSC 9601, November.

[3] Benjamin. H.R and Williams.H., " Behavior of one storey walls containing openings", Journal of American Concrete Institute, Vol- 30, No-5, Nov 1958, pp 162169.

[4] Choubey, U.B., and Sinha, S.N., (1994), "Cyclic Response of Infilled Frames," Journal of Structural Engineering, Vol. 21, No. 3, October, pp. 203-211.

[5] FEMA-273, (1997), NEHRP Guidelines for the Seismic Rehabilitation of Buildings, Federal Emergency Management Agency, Washington, D. C, October.

[6] Goutam Mondal and S.K.Jain (2008)," Lateral Stiffness of Masonry Infilled RC Frame with Central Opening", Earthquake Spectra, Vol. 24, N0.3, PP.701-723,Aug 2008

[7] Holmes, M., (1961), "Steel Frames with Brickwork and Concrete Infilling," Proceedings of the Institution of Civil Engineers, Vol. 19, August, pp. 473-478

[8] King G.J.W and Pandey D.C., " The Analysis of Infilled Frame using Finite elements", Proceedings of the Institution of Civil Engineers, part 2,65, Dec 1978 ,PP 749-760

[9] K S Jagadish, B V Venkatarama Reddy and K S Nanjunda Rao "Alternative Building Materials \& Technologies".

[10] Liauw, T.C., (1972), "An Approximate Method of Analysis for Infilled Frames with or without Opening," Building Science, Vol. 7, pp. 233-238.

[11] Liauw, T.C., (1979), “Tests on Multi-storey Infilled Frames Subject to Dynamic Lateral Loading," ACI Journal, Title No. 76-26, April, pp. 551-563

[12] Mainstone, R.J., (1971), "On the Stiffness and Strengths of Infilled Frames", Proceedings of the Institution of Civil Engineers, Supplement IV, Paper No. 7360S, pp. 57-90.

[13] Malick, D.V., and Garg, R.P., (1971), "Effect of Openings on the Lateral Stiffness of Infilled Frames," Proceedings of the Institution of Civil Engineers, Vol. 49, Part-2, Paper No. 7371, June, pp. 193-209.
[14] Mallik D.V. and Severn R.T, "Behavior of Infilled frame under static Loading", Proceeding of the Institution of Civil Engineers, Vol.38, 1967, PP 639656.

[15] Meharbi Armin B and Benson Shing P, "Finite Element Modeling for Masonry-Infilled RC Frames", Journal of Structural Engineering, Vol.19, No.7. Jul 1997.PP576585

[16] Pankaj Agarwal, " Earthquake resistance design of structures"

[17] Polyakov S.V., 'On the Strength And Deformation Of Masonry Infilling In Framed Walls Under Shearing Load; Building Industry, No3, Moscow, 29-52

[18] Perumal Pillial E.B., Govindan P.,'Structural Response Of Brick Infill In R.C Frames.'Internation Journal Of Structural', vol.14, No 2, Dec 1994. 